\title{
Development of a Graphical User Interface to Visualize Upper-Air Meteorological Data
}

by

R. L. Buckley

Westinghouse Savannah River Company

Savannah River Site

Aiken, South Carolina 29808

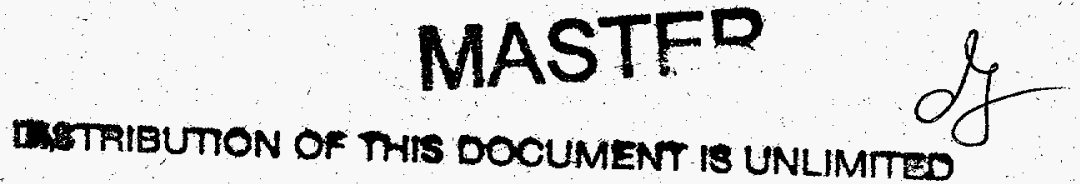

DOE Contract No. DE-AC09-96SR18500

This paper was prepared in connection with work done under the above contract number with the U.S.

Department of Energy. By acceptance of this paper, the publisher and/or recipient acknowledges the U.S. Government's right to retain a nonexclusive, royalty-free license in and to any copyright covering this paper, along with the right to reproduce and to authorize others to reproduce all or part of the copyrighted paper. 


\section{DISCLAIMER}

This report was prepared as an account of work sponsoned by an agency of the United States Government. Neither the United States Government nor any agency thereof, nor any of their employees, makes any warranty, express or implied, or assumes any legal liability or -responsibility for the accuracy, completeness, or usefulness of any information, apparatus, product, or process disclosed, or represents that its use would not infringe privately owned rights. Reference herein to any specific commercial product, process, or service by trade name, trademark, manufacturer, or otherwise does not necessarily constitute or imply its endorsement, recommendation, or favoring by the United States Government ar any agency thereof. The views and opinions of authors expressed herein do not necessarily state or reflect those of the United States Govemment or any agency thereof.

This report has been reproduced directly from the best available copy.

Available to DOE and DOE contractors from the Office of Scientific and Technical Information, P.O. Box 62, Oak Ridge, TN 37831; prices available from (615) 576-8401.

Available to the public from the National Technical-Information Service, U.S. Department of Commerce, 5285 Port Royal Road, Springfield, VA 22161. 


\section{DISCLAIMER}

Portions of this document may be illegible electronic image products. Images are produced from the best available original document. 


\section{DEVELOPMENT OF A GRAPHICAL USER INTERFACE TO VISUALIZE UPPER-AIR METEOROLOGICAL DATA (U)}

Robert L. Buckley

Technical Reviewer

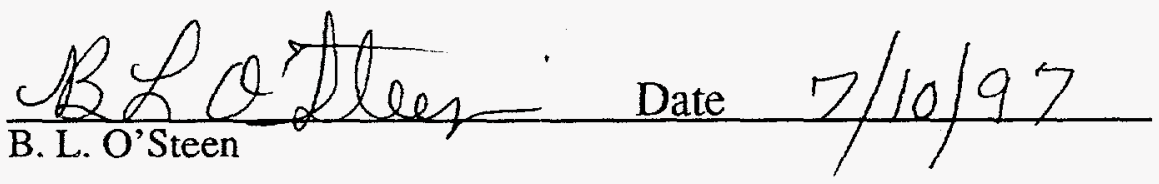

Approval
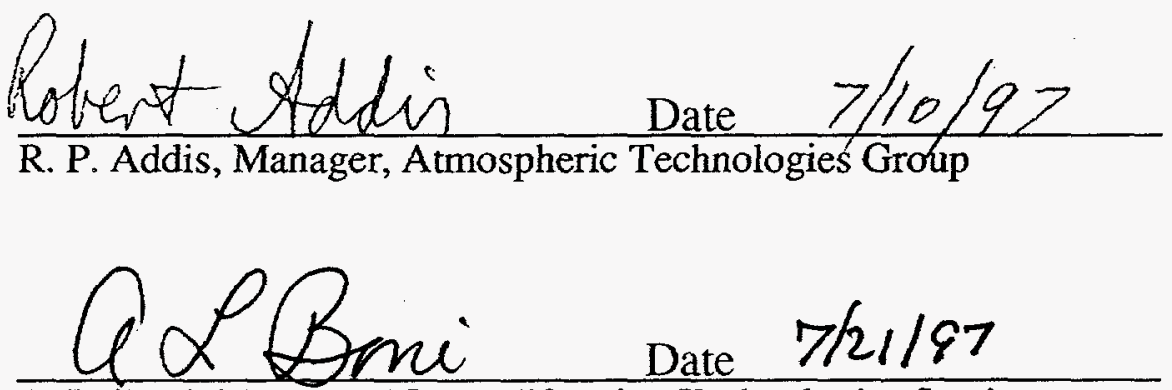

A. L. Boni, Manager, Nonproliferation Technologies Section

July 1997

Westinghouse Savannah River Company

Savannah River Site

Aiken, SC 29808

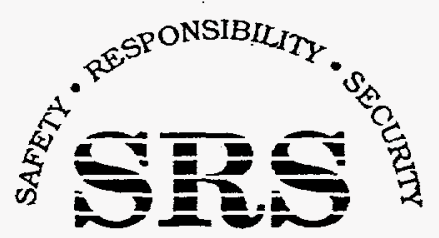

SAVANNAH RIVER SITE

PREPARED FOR THE U.S. DEPARTMENT OF ENERGY.UNDER CONTRACT NO. DE-AC09-96SR18500 
Key Words Meteorology

Upper-air data

Graphical user interface

Thermodynamic diagram

Retention: Lifetime

\section{DEVELOPMENT OF A GRAPHICAL USER INTERFACE TO VISUALIZE UPPER-AIR METEOROLOGICAL DATA (U)}

Robert L. Buckley

Issued: July 1997

SRTC

SAVANNAH RIVER TECHNOLOGY CENTER

AIKEN, SC 29808

Westinghouse Savannah River Company

Savannah River Site Aiken, SC 29808

PREPARED FOR THE U.S. DEPARTMENT OF ENERGY UNDER CONTRACT NO. DE-AC09-96SR18500 


\section{ABSTRACT}

Upper-air meteorological data (soundings) are often analyzed by means of thermodynamic diagrams relating temperature, humidity and atmospheric pressure. This report describes the components of a graphical user interface which have been developed to visualize soundings in this manner at any global location and time of interest. 


\section{TABLE OF CONTENTS}

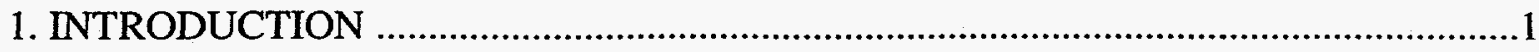

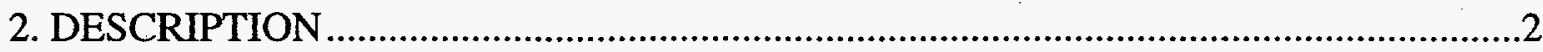

3. COMPONENTS OF THE CODE

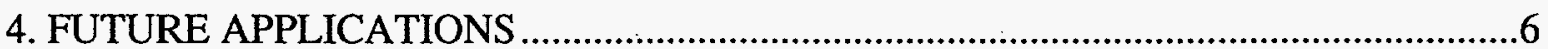

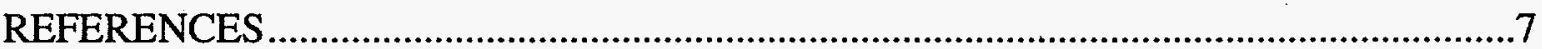




\section{LIST OF FIGURES}

Figure 1: Determination of the area ('box') in which upper-air data is selected based on user input of center latitude $\left(\mathrm{C}_{\mathrm{LAT}}\right)$, center longitude $\left(\mathrm{C}_{\mathrm{LON}}\right)$, and range $(R)$.

Figure 2: Flow diagram of the upper-air graphical user interface program.

Figure 3: Screen image of the graphical user interface for a user-selected time (04 June $1997,00 \mathrm{Z})$ and location $\left(\mathrm{C}_{\mathrm{LAT}}=35^{\circ}, \mathrm{C}_{\mathrm{LON}}=-93^{\circ}, R=1000 \mathrm{~km}\right)$ showing a sounding for Springfield, Missouri. 


\title{
DEVELOPMENT OF A GRAPHICAL USER INTERFACE TO VISUALIZE UPPER-AIR METEOROLOGICAL DATA (U)
}

\author{
Robert L. Buckley \\ Westinghouse Savannah River Company \\ Savannah River Site \\ Aiken, SC 29808
}

\section{INTRODUCTION}

The Atmospheric Technologies Group (ATG) of the Savannah River Technology Center (SRTC) currently collects and archives a considerable amount of data from Weather Services International (WSI) on a daily basis. Both surface and upper-air observations are collected by governmental agencies around the world at varying time intervals $(1,3$, or 12 hours). The upper-air (sounding) data are collected at 12-hr increments worldwide from stationary and mobile (ship) locations. It is important to be able to present the information contained in these data to an interested customer in a quick, efficient manner. This report focuses on the graphical display of the upper-air data from stationary locations.

A particularly effective way of illustrating weather conditions at a given upper-air location is through the use of thermodynamic diagrams relating pressure, temperature and moisture. Meteorologists frequently use a 'skew- $T \log _{-} p$ ' diagram containing a logarithmic pressure $(p)$ scale along the ordinate and temperature $(T)$ skewed at an angle to the right along the abscissa. Mathematically, the axes are described by $(T-K \ln p,-\ln p)$, where $K$ is a positive constant.

The need for such diagrams is to convey information regarding upper-air temperatures and lapse rates. A lapse rate refers to the change in air temperature with height (i.e. pressure, assuming a hydrostatic atmosphere). If a small mass of dry air (parcel) changes temperature solely with height (and not due to processes such as conduction, radiation, or convective mixing), the process is said to be adiabatic. For an adiabatic process, the temperature of an air parcel will cool as it rises and warm as it descends. Therefore, a dry adiabatic line (or dry adiabat) describes the temperature variation of a dry air parcel with height. Equal areas on a skew- $T$ log- $p$ thermodynamic diagram represent equal energy. This makes the diagrams powerful tools in analyzing atmospheric convection.

If water vapor exists in a rising air parcel, a level is eventually reached where sufficient cooling occurs to cause saturation of the parcel. The temperature at which this saturation occurs is the dew point. Above this level, condensation of surplus moisture occurs. The latent heat associated with this phase change reduces the adiabatic cooling rate of dry ascending air. Saturated adiabats are thus used to indicate the temperature variation of the saturated air parcel with height (Meteorological Office, 1971). The dry and saturated adiabats are commonly plotted on the skew- $T \log -p$ diagram. In addition, lines of constant saturation mixing ratio (the ratio of the mass of water vapor in a unit mass of dry air $(\mathrm{g} / \mathrm{kg}))$ are illustrated in the diagrams.

The upper-air data typically consists of dry-bulb temperature and dew point temperature as a function of pressure (height). By superimposing dry-bulb and dew point temperature values on the skew- $T \log -p$ diagram containing both dry and saturated adiabats, 
information regarding atmospheric stability and convective formation can be discerned (Bluestein 1992). Also, wind barbs indicating the wind speed and direction of horizontal flow for a given pressure level may be plotted on the diagram, yielding further atmospheric information to the user.

A device for depicting this information has been developed using the Interactive Data Language (IDL). The user is prompted for the time and general location of upper-air interest. Once this is known, possible sounding locations are determined and the user is then given the option of examining one or more stations in the region. The procedures which the user follows are dictated by a graphical user interface (GUI). The purpose of this report is to briefly describe this interface, its various components and possible future applications.

\section{DESCRIPTION}

The use of a menu-driven GUI allows the user to more easily input and display upper-air soundings than a code requiring specific keyboard inputs. A series of 'widget' procedures within IDL (version 4.0.1, IDL User's Guide, 1995) is used to create the GUI. This involves creating a 'base' widget upon which other widgets of varying complexity and design are used to carry out a function and/or display an image. The basic code structure is in the form of a series of procedures and functions. Note that procedures within the IDL programming language are equivalent to Fortran subroutines.

The user is first prompted to select a time and central location from which to examine upper-air data. Sounding data is then gathered in a user-specified region about this central location. The center location is entered as a latitude and longitude. The center latitude values must be between $-90^{\circ}$ and $+90^{\circ}$ where negative quantities imply a center point within the southern hemisphere and positive quantities within the northern hemisphere. Likewise, the center longitude must be between $-180^{\circ}$ and $+180^{\circ}$ with western hemisphere locations denoted by negative numbers and eastern hemisphere places given by positive numbers.

Data is archived from WSI at 00 and 12 Greenwich Mean Time (GMT, often reported as $\mathrm{Z}$ (Zulu) time). Data from all reporting stations worldwide is contained within a given file (named with respect to the time). (Note that $06 \mathrm{Z}$ data (obtained mainly from European countries) is contained within the $12 \mathrm{Z}$ files, while the $18 \mathrm{Z}$ data is contained within the $00 \mathrm{Z}$ files). The $\mathrm{IDL}$ procedure pickfile.pro is utilized and prompts the user to enter a selection from a list of files in a given directory containing the WSI upper-air data. The format of the filenames is 'mmddyyyy_hhZ' where ' $m$ ' ' is the month in integer form $(01,02, \ldots, 12)$, 'dd' is the day, 'yyyy' is the year, and ' $h$ ' is the hour, corresponding to GMT or Z.

The sampling range $(\mathrm{km})$ is used to determine maximum and minimum latitudes and longitudes from which to sample possible upper-air stations and is limited to less than $10000 \mathrm{~km}$. The range refers to the total distance from west-to-east and from north-tosouth running through the center latitude and longitude. Thus, if a range of $100 \mathrm{~km}$ is selected, points up to $50 \mathrm{~km}$ east and $50 \mathrm{~km}$ west would be included. Note that the 'box' from which stations are selected is actually one of constant latitude along the top and bottom, and one of constant longitude along the right and left sides of the domain. This is illustrated in Fig. 1 for a center point located within the northern hemisphere. Note that the domain of interest is not allowed to extend over either of the poles, but is instead assumed to stop at the pole. 
After the time and location of upper-air examination is satisfactorily entered, a map is drawn showing the countries (continents) in which soundings are desired. A datafile containing the latitude, longitude, elevation, and city/country associated with a unique 5digit integer station identification (station ID) is then accessed. Each station ID within the selected area (Fig. 1) is also shown on the map. If the user wishes to examine a portion of the map image in greater detail, a 'zoom' button may be selected which will magnify a user-selected location within the image.

If stations exist within the domain of interest, the program then searches the given time file for data associated with these stations. For those stations with upper-air data at the given time, a separate widget is created containing a list of station ID 'buttons'. The user may then select the button for the station of interest. After selection, the data is decoded and a thermodynamic (skew- $T \log -p$ ) diagram is created with temperature and dew point $\left({ }^{\circ} \mathrm{C}\right)$ superimposed on the diagram.

Two types of datasets are queried as defined by the World Meteorological Organization (WMO): Part A and Part B (Federal Meteorological Handbook No. 4, 1976). These datasets contain geopotential height, temperature, dew point depression, wind speed and wind direction at given pressure levels from the surface to $100 \mathrm{mbar}$. If wind data is available (Part A only), wind barbs are also plotted on the sounding. Magnification of the sounding for a selected area within the image is available, as well as an option to hardcopy the sounding. If the latter is desired, a postscript file is created from the image and may be output to a local printer. At this point, the user may select other stations to view for the given time, or select a new time and/or place from which to examine sounding data.

A flow diagram of the GUI is shown in Fig. 2. Special features which allow the user to examine a portion of the sounding or mapped area are included in the diagram. This magnification utilizes a modification of the IDL procedure zoom.pro.

Figure 3 is a screen-dump image of the GUI showing the various components. The time and location is input in the upper left portion. When the program is executed, this is the only part of the GUI which is visible to the user. After successful data entry, a map is produced in the top center, with station locations and other pertinent information depicted. This particular plot is centered about Little Rock, Arkansas and contains 8 stations. Those stations which contain data for the selected time are indicated in the upper right portion of the figure. An area containing comments and instructions to the user is shown in both the upper left and upper right areas in the lighter regions.

The thermodynamic diagram is shown in the bottom half of the widget, with dew point temperature shown in yellow, and dry-bulb temperature in white. Saturated adiabats $\left({ }^{\circ} \mathrm{C}\right)$ are solid dark blue lines which curve from right to left with decreasing pressure (and labeled at $700 \mathrm{mbar}$ ). The temperature for this sounding closely follows the $20^{\circ} \mathrm{C}$ saturated adiabat. Dry adiabats are given by the solid red lines extending from right to left with decreasing pressure. Finally, the saturation mixing ratio $(\mathrm{g} / \mathrm{kg})$ is denoted by the dashed green lines with value labels at 1000 and 200 mbar. This sounding indicates a temperature increase (i.e. inversion) between 850 and 800 mbar and a dryer atmosphere between 800 and 500 mbar. Wind barbs are indicated to the right, with a 'plus' denoting the maximum wind speed for all of the levels shown ( $250 \mathrm{mbar}$ in this sounding). In the lower right hand corner, the user is reminded of the values for the feathers and flags as placed on the wind barbs. In addition, each component of the GUI has a widget button which allows the user to unmap it. To exit the GUI completely, the 'EXIT' widget button in the upper left portion must be depressed. 


\section{COMPONENTS OF THE CODE}

The various procedures and functions used or developed for this application are briefly described in this section.

barb_plot.pro: This procedure plots wind barbs on the skew- $T \log -p$ diagram using the known wind speed and directions at various pressure levels. Short feathers are 2.5 $\mathrm{m} / \mathrm{s}$, long feathers are $5.0 \mathrm{~m} / \mathrm{s}$, and flags are $25 \mathrm{~m} / \mathrm{s}$. Maximum winds plotted are 50 $\mathrm{m} / \mathrm{s}$. Thus, winds greater than this are also represented by 2 flags. Calm winds $(<1.0$ $\mathrm{m} / \mathrm{s}$ ) are represented by hollow circles.

country_sel.pro: This procedure determines a country name based on a 2-character country abbreviation taken from the list of WMO 5-digit station ID's.

drawing.pro: This procedure determines an offset (stretching of the mapping domain) to allow the user to view a larger context of the selected domain. The IDL mapping procedure 'map_set.pro' is then called to draw the country (or state) and continent outlines of the region. Station ID's and their locations are plotted on the map, along with the domain size, center latitude/longitude coordinates, and the number of stations within the selected area.

driver.pro: This is the main driver for the entire widget-driven program. It creates the base ('parent') widget and all other ('children') widgets under it. In Fig. 3, this 'parent' widget encompasses the entire image and is labeled 'UPPER-AIR ILLUSTRATIONS'. The information structure 'info' is created in this module and is passed among the widgets and procedures. Values for the various parameters needed within the different procedures (e.g. location and time) are stored in this structure, similar to 'common' blocks used in Fortran. An 'event handler' is used in the widget program to perform tasks based on user input (i.e. what action must be taken if a particular widget button is selected). All major decisions are controlled within this event handler. This includes error checking of input data, the existence of stations within the chosen area, the existence of data for the given station ID and time, whether to zoom in on various images, which station ID data to plot, as well as creating hardcopy output.

function map_get: This function is called by a widget drawing procedure to plot the map boundaries and possible station ID's falling within the 'box.' Within this function a procedure is called ('drawing.pro') which does the mapping and plotting. The boundaries of the 'box' are plotted in the function (see the widget in Fig. 3 labeled 'MAP of REGION of INTEREST').

function snd_draw_get: This function is called by a widget drawing procedure to plot the upper-air sounding. The requested datafile (time) is opened and the selected station ID (selection performed from the event handler of 'driver.pro') is found. The WMO-defined Part A and Part B datasets are searched. Procedures are called to decode the data strings to obtain the information for plotting. A thermodynamic (skew- $T \log -p$ ) diagram is plotted and dry-bulb temperature and dew point temperature values are plotted on a transformed (skewed) coordinate system. If wind data exists, a wind-barb plotting procedure is called to display this information next to the sounding (see the bottom of Fig. 3). 
function tnew: This function converts the dry-bulb and dew point temperature values to the skewed coordinate system used by 'skewt.pro'. The temperature axis in this application is skewed by $63.4^{\circ}$ relative to the horizontal, as illustrated in Fig. 3 by the solid black temperature lines extending from left to right with decreasing pressure.

latlon_get.pro: This procedure determines the latitude/longitude bounds based on user input. If the range is chosen such that the domain would cross over either the North or South pole, then the range is reduced to stop at the poles. Therefore, the user is cautioned not to select a latitude near the poles, as the size of the domain is severely reduced and very few stations exist at these locations. In addition, the possible problems at longitude crossover from $+180^{\circ}$ to $-180^{\circ}$ must be handled here. To reduce computing time, if a large range is chosen (i.e. $>5000 \mathrm{~km}$ ), the number of stations is limited to 50 . With a large number of stations, the map tends to becomes cluttered reducing its effectiveness in imparting information to the user.

skewt.pro: This procedure draws the skew- $T$ log- $p$ diagram from a given temperature range of data. Also drawn on the plot are saturated and dry adiabats, and mixing ratio lines.

ttaa_get.pro: This procedure decodes the Part A dataset consisting of geopotential height (m), temperature (C), dew point depression (C), wind direction (deg), and wind speed ( $\mathrm{knots}$ or $\mathrm{m} / \mathrm{s}$ ) at mandotory pressure levels (mbar). The string containing all of the data for a given station is reduced in length by first removing all extraneous spaces. Data is then stored in 5-character sequences as described in detail in World Meteorological Organization (WMO) documention (Federal Meteorological Handbook No. 4, 1976). Arrays containing the meteorological information, as well as the number of pressure levels containing valid data are returned to 'function snd_draw_get.'

ttbb_get.pro: This procedure decodes the Part B dataset consisting of temperature (C) and dew point depression (C) at significant pressure levels (mbar). The string containing all of the data for a given station is reduced in length by first removing all extraneous spaces. Data is then stored in 5-character sequences as described in detail in World Meteorological Organization (WMO) documention (Federal Meteorological Handbook No. 4, 1976). Arrays containing the meteorological information, as well as the number of pressure levels containing valid data are returned to 'function snd_draw_get.'

\section{FUTURE APPLICATIONS}

It would be of interest to determine a vertical profile of the atmosphere for a location in which stations do not exist without resorting to a model-generated source (such as the National Meteorological Center's Aviation or Eta models). For example, upper-air data at the Savannah River Site could be determined using information from Charleston (South Carolina) to the southeast, Greensboro (North Carolina) to the northeast, Atlanta (Georgia) to the west-northwest, and Waycross (Georgia) to the southwest. Interpolation techniques already developed (Walko et al. 1993) could be used to determine values of dry-bulb temperature, dew point, and winds at different pressure levels. Within the GUI, the user would input the latitude and longitude of the location in which the profile is desired, as well as the range from which to gather data for interpolation. The interpolation scheme would need to be added to the GUI coding, as well as errorchecking for missing data. 
This could produce misleading results if a frontal boundary exists between stations. Therefore, a possible extension to this application would be to examine a time-series of soundings for the stations in the local domain using a history of times perhaps 24 to 48 hours prior to the selected time. 


\section{REFERENCES}

Bluestein H. B., Synoptic-Dynamic Meteorology in Midlatitudes, Volume I: Principles of Kinematics and Dynamics (1992), Oxford Press University, Inc., 431 pp.

Federal Meteorological Handbook No. 4. Radiosonde Code, Second Edition, (Jan. 1976) U.S. Department of Commerce, U.S. Department of Defense, U.S. Department of Transportation, Washington D.C.

IDL User's Guide, Interactive Data Language, Version 4 (March 1995), Research System Inc., Boulder CO.

Meteorological Office (Roberts E. D.), Handbook of Aviation Meteorology, Second Edition (1971), Her Majesty's Stationery Office, London UK, 404 pp.

Walko R. L., C. J. Tremback, and R. F. A. Hertenstein (1993). RAMS--The Regional Atmospheric Modeling System, Version 3a, User's Guide. ASTeR, Inc., Fort Collins, $\mathrm{CO}, 100 \mathrm{pp}$. 


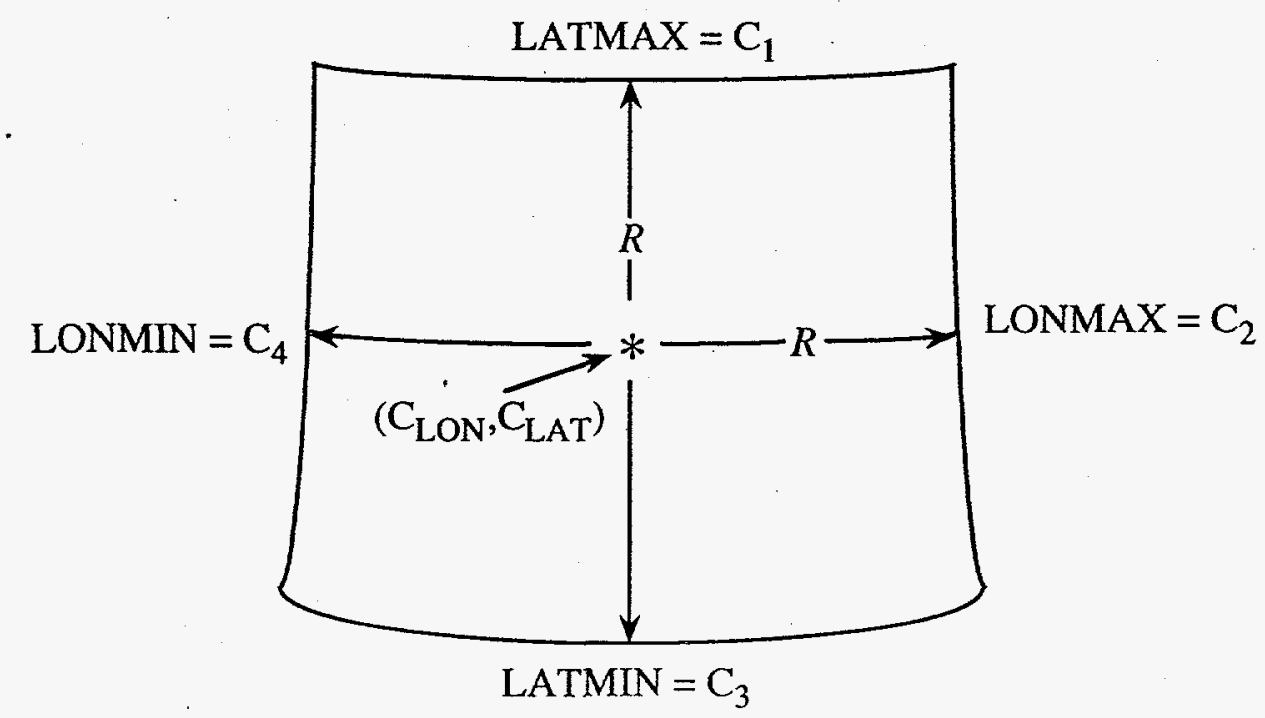

Figure 1: Determination of the area ('box') in which upper-air data is selected based on user input of center latitude $\left(\mathrm{C}_{\mathrm{LAT}}\right)$, center longitude $\left(\mathrm{C}_{\mathrm{LON}}\right)$, and range $(R)$ 


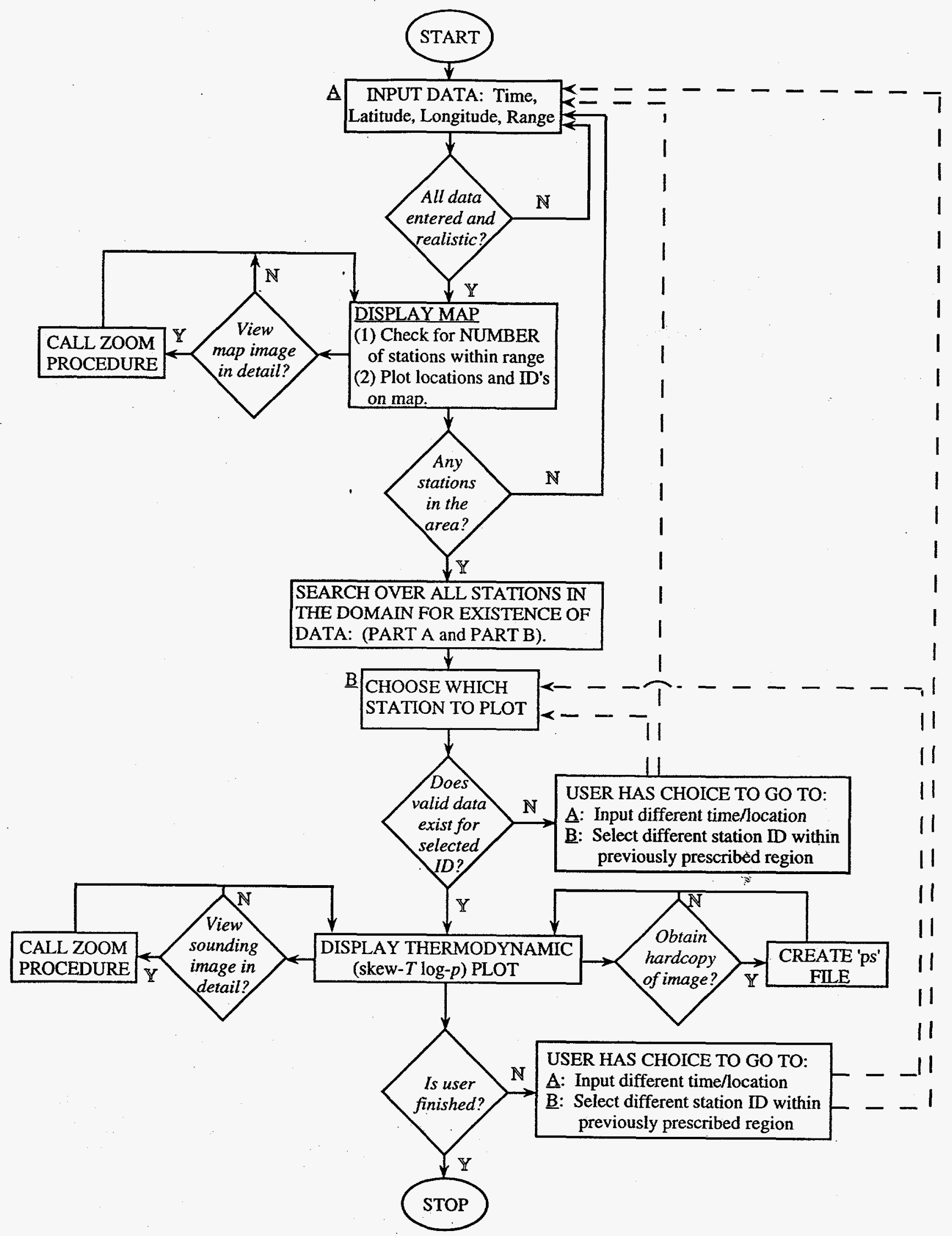

Figure 2: Flow diagram of the upper-air graphical user interface program 


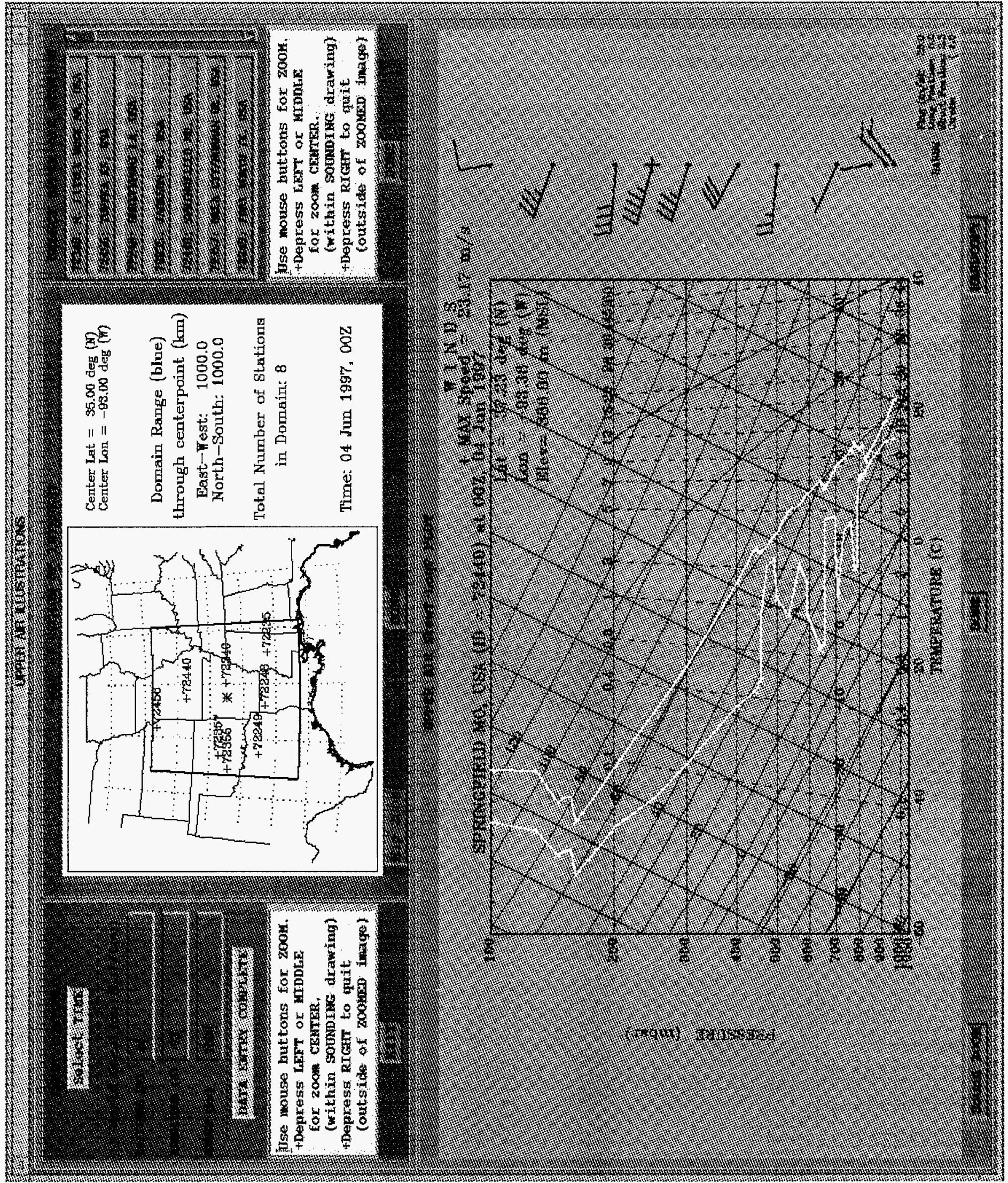




\section{DEVELOPMENT OF A GRAPHICAL USER INTERFACE TO VISUALIZE UPPER-AIR METEOROLOGICAL DATA (U)}

\section{DISTRIBUTION}

P. Deason, 773-A

A. L. Boni, 773-A

R. P. Addis, 773-A

A. J. Garrett, 773-A

D. P. Griggs, 773-A

C. H. Hunter, 773-A

R. J. Kurzeja, 773-A

M. J. Parker, 735-7-A

B. L. O'Steen, 773-A

A. H. Weber, 773-A

R. L. Buckley, 773-A

SRTC Records(4), 773-52A

ETG Records(5), 773-A 